\title{
MicroRNA-663b enhances migration and invasion by targeting adenomatous polyposis coli 2 in colorectal carcinoma cells
}

\author{
FENQIANG XIAO $^{1}$, WANGBIN $\mathrm{CHEN}^{2}, \mathrm{CHAO} \mathrm{YU}^{3}$ and GANG ZHAO ${ }^{1}$ \\ ${ }^{1}$ Department of Emergency Surgery, ${ }^{2}$ Cancer Center and ${ }^{3}$ Department of Medical Laboratory, Union Hospital, \\ Tongji Medical College, Huazhong University of Science and Technology, Wuhan, Hubei 430022, P.R. China
}

Received May 7, 2019; Accepted December 12, 2019

DOI: $10.3892 / \mathrm{ol} .2020 .11482$

\begin{abstract}
Colorectal carcinoma (CRC) is one of the leading causes of cancer-associated mortality worldwide. Dysregulation of microRNA (miR)-663b has been reported in a variety of diseases. However, the specific biological function of miR-663b in $\mathrm{CRC}$ requires further investigation. The aim of the present study was to elucidate the role and underlying molecular mechanism of action of miR-663b in CRC. Reverse transcription-quantitative polymerase chain reaction (RT-qPCR) analysis and western blot analysis were employed to measure the expression of miR-663b at the RNA and protein level, respectively. Flow cytometry was used to detect cell apoptosis. Cell proliferation, migration and invasion were evaluated by the Cell Counting Kit-8, wound healing and Transwell assays, respectively. A dual-luciferase reporter assay was used to validate the potential target gene of miR-663b. The expression of miR-663b was identified to be markedly upregulated in CRC cells. Ectopic miR-663b expression promoted CRC cell proliferation, migration and invasion, and inhibited apoptosis. The dual-luciferase reporter assay identified adenomatous polyposis coli 2 (APC2) as a direct target of miR-663b in CRC cells. Further investigation indicated that miR-663b was involved in CRC cell invasion through the $\mathrm{Wnt} / \beta$-catenin pathway. Therefore, overexpression of miR-663b was able to promote CRC cell proliferation, migration and invasion by regulating the $\mathrm{Wnt} / \beta$-catenin pathway through targeting APC2, suggesting that miR-663b may be a useful target for the diagnosis and treatment of CRC.
\end{abstract}

\section{Introduction}

Colorectal carcinoma (CRC) is the third leading cause of cancer-associated mortality worldwide $(1,2)$. A total of

Correspondence to: Professor Gang Zhao, Department of Emergency Surgery, Union Hospital, Tongji Medical College, Huazhong University of Science and Technology, 1277 Jiefangdadao Avenue, Wuhan, Hubei 430022, P.R. China

E-mail: gangzhao@hust.edu.cn

Key words: microRNA-663b, colorectal carcinoma, adenomatous polyposis coli 2 , invasion, $\mathrm{Wnt} / \beta$-catenin $\sim 1$ million patients are diagnosed with CRC and $\sim 50 \%$ succumb to this malignancy annually worldwide (3). The development of CRC is a complex process involving multiple genetic and epigenetic changes. Although some have already been identified, novel molecules that have been implicated in CRC carcinogenesis, and may be crucial for the diagnosis and treatment of $\mathrm{CRC}$, require further investigation. Therefore, it is imperative to elucidate the mechanisms underlying CRC tumorigenesis and to identify new molecules involved in its development and progression.

MicroRNAs (miRNAs) are endogenous non-coding RNAs, which exert their effects by binding to the 3'untranslated regions (3'UTRs) of target mRNAs (4,5). miRNAs are involved in various processes such as gene regulation, apoptosis, hematopoietic development, cell differentiation and tumorigenesis (4). Additionally, various types of human cancer, including CRC, have been associated with the dysregulation of miRNAs (6-8). Accumulating evidence indicates that miRNAs may serve as potential oncogenes or tumor suppressor genes in tumorigenesis (9-12).

Shen et al (13) demonstrated that miR-139 inhibits invasion and metastasis of CRC cells by regulating the type I insulin-like growth factor receptor. Xu et al (14) observed that miR-503-5p confers drug resistance by targeting p53 upregulated modulator of apoptosis in CRC. Recently, Pellatt et al (15) used microarray analysis to demonstrate that miR-663b was significantly overexpressed in CRC tissues compared with the normal mucosa. However, the mechanism of action of miR-663b in CRC remains elusive.

The aim of the present study was to investigate the expression of miR-663b in CRC cell lines compared with normal colonic cells, determine its effects on CRC cell proliferation, migration, invasion and apoptosis in vitro, and elucidate the underlying mechanism of action, in order to determine whether miR-663b serves as an oncogene in CRC and identify a potential new target for CRC diagnosis and treatment.

\section{Materials and methods}

Tissue specimens, cell lines and transfection. A total of 20 paired CRC and adjacent normal tissue specimens were obtained from the Department of General Surgery, Union Hospital, Tongji Medical College, Huazhong University of Science and Technology. The tissue samples were frozen in 
liquid nitrogen immediately following surgical removal and stored at $-80^{\circ} \mathrm{C}$ until used. The study protocol was approved by the Ethics Committee of Tongji Medical College, Huazhong University of Science and Technology (IORG no. IORG0003571) and written informed consent was obtained from each participant. The human CRC HT-29, HCT-116, SW480 and SW620 cell lines, and the normal colonic FHC cell line, were obtained from American Type Culture Collection. The HT-29 cell line used in our study has been authenticated using the method of STR profiling. All cell lines were maintained under the recommended culture conditions and incubated in a humidified environment with $5 \% \mathrm{CO}_{2}$ at $37^{\circ} \mathrm{C}$. The gain-of-function study of miR-663b was conducted with miR-663b mimics (100 $\mathrm{nM})$ and corresponding negative control $(100 \mathrm{nM})$ on the SW480 cell line. The loss-of-function assay was conducted with miR-663b inhibitor (100 nM) and corresponding negative control $(100 \mathrm{nM})$ on the HCT-116 cell line. miR-663b mimics, miR-663b inhibitors and the corresponding negative control were purchased from Shanghai GenePharma Co., Ltd. The sequences of the miR-663b mimic and the inhibitor were as follows: GGUGGCCCGGCCGUG CCUGAGG and CCUCAGGCACGGCCGGGCCACC, respectively. All assays were performed using Lipofectamine ${ }^{\circledR}$ 2000 (Invitrogen; Thermo Fisher Scientific, Inc.). Subsequent experimentations were performed $48 \mathrm{~h}$-post transfection.

Oligoribonucleotides. All the oligoribonucleotides used in the present study were purchased from Shanghai GenePharma Co., Ltd. (Table I). The small interfering (si)RNA targeting human adenomatous polyposis coli 2 (APC2) transcript was designated as siAPC2.

$R N A$ extraction and reverse transcription-quantitative (RT-q) $P C R$ analysis. Total RNA was isolated from the cells using TRIzol ${ }^{\circledR}$ reagent (Thermo Fisher Scientific, Inc.), according to the manufacturer's protocol. RT-qPCR was performed to evaluate the expression of miR-663b and APC2 mRNA in SW480 and HCT-116 cells. RNA was reverse transcribed using One Step PrimeScript miRNA cDNA Synthesis kit (Takara Bio, Inc.). cDNA was subsequently quantified via qPCR using SYBR Premix Ex Taq (Takara Bio, Inc.). All PCR reactions were performed using the ABI7500 system (Applied Biosystems; Thermo Fisher Scientific, Inc.). The thermocycling conditions were as follows: Initial denaturation at $95^{\circ} \mathrm{C}$ for $5 \mathrm{~min}$; 40 cycles of $95^{\circ} \mathrm{C}$ for $15 \mathrm{sec}$; annealing/elongation at $60^{\circ} \mathrm{C}$ for $30 \mathrm{sec}$ and a final extension at $72^{\circ} \mathrm{C}$ for $30 \mathrm{sec}$. The relative expression levels of miR-663b and APC 2 mRNA were quantified using the $2^{-\Delta \Delta \mathrm{Cq}}$ method (16) and normalized to small nuclear RNA U6 and GAPDH, respectively.

Western blot analysis. Protein was prepared from transfected SW480 and HCT-116 cells using modified RIPA lysis buffer supplemented with proteinase inhibitor cocktail (Sangon Biotech Co, Ltd.). Protein concentrations were measured according to the BCA protein assay kit (Beyotime Institute of Biotechnology). Equal protein amounts (30-50 $\mu \mathrm{g}$ ) were separated in $10 \%$ SDS-PAGE gels and transferred onto polyvinylidene fluoride membranes. The membranes were blocked with $5 \%$ non-fat milk for $1 \mathrm{~h}$ at room temperature, prior to incubation overnight at $4{ }^{\circ} \mathrm{C}$ with the following primary antibodies: Anti-APC2 (cat. no. 12301), anti-c-Myc (cat. no. 9402), anti-phospho- $\beta$-catenin (Ser552; cat. no. 9566), anti-phospho- $\beta$-catenin (Ser675; cat. no. 9567), anti- $\beta$-catenin (cat. no. 9562), anti-cyclin D1 (cat. no. 2922), anti-axin1 (cat. no. 2087) and anti- $\beta$-actin (cat. no. 4970) (all 1:1,000 and all from Cell Signaling Technology, Inc.). The membranes were subsequently washed 3 times in $10 \mathrm{ml}$ TBS $+0.2 \%$ Tween-20 and incubated with the corresponding horseradish peroxidase-conjugated secondary antibody (1:5,000; cat. no. D110291; Sangon Biotech Co., Ltd.) for $1 \mathrm{~h}$ at room temperature. Secondary antibody binding to the primary antibody was detected using an enhanced chemiluminescence system (Pierce; Thermo Fisher Scientific, Inc.). All experiments were performed in triplicate.

Cell proliferation assay. SW480 and HCT-116 cells seeded at a density of 4,000 cells/well in 96-well plates were transfected with $\mathrm{miR}-663 \mathrm{~b} \mathrm{mimic} / \mathrm{miR}-663 \mathrm{~b}$ inhibitor or corresponding NC. Following incubation of the cells for the specified time (1, 2, 3 or 4 days), a Cell Counting Kit- 8 assay was performed according to the manufacturer's protocol (Dojindo Molecular Technologies, Inc.). The absorbance of the solution was measured spectrophotometrically at $450 \mathrm{~nm}$ with MRX II absorbance reader (Dynex Technologies). All experiments were performed in triplicate.

Wound healing assay. The migration of SW480 or HCT-116 cells was assessed via the wound healing assay. A total of $5 \times 10^{5}$ cells were seeded into 6 -well plates and cultured in DMEM medium (Sangon Biotech Co, Ltd.) at $37^{\circ} \mathrm{C}$ in $5 \% \mathrm{CO}_{2}$ until they reached $\sim 100 \%$ confluence. Subsequently, artificial wounds were created by scratching the cell monolayer with a sterile pipette tip. Following wounding, cells were washed three times with PBS to remove floating cells and debris, and subsequently incubated in serum-free medium at $37^{\circ} \mathrm{C}$ in $5 \% \mathrm{CO}_{2}$. Representative images with cells migrating into the wounds were randomly captured using an inverted light microscope (magnification, x40). The experiments were performed in triplicate.

Transwell invasion assay. Transwell membranes (Corning, Inc.) coated with Matrigel (BD Biosciences, USA) were used to assay cell invasion in vitro. A total of $1.0 \times 10^{5}$ transfected cells suspended in serum-free medium were added to the upper chamber, and medium supplemented with $10 \%$ FBS (Sangon Biotech Co., Ltd.) was added to the lower chamber as a chemoattractant. After $24 \mathrm{~h}$ of incubation at $37^{\circ} \mathrm{C}$, the invading cells were fixed with $4 \%$ paraformaldehyde for $30 \mathrm{~min}$, followed by staining with $0.1 \%$ crystal violet solution for $20 \mathrm{~min}$, both at room temperature. Subsequently, each well was captured using an inverted light microscope (magnification, x100). Data were obtained from three independent experiments.

Apoptosis assay. An Annexin V-fluorescein isothiocyanate (FITC) Apoptosis Detection Kit (Beyotime Institute of Biotechnology) was used to analyze the cell apoptosis rate according to the manufacturer's instructions. Following transfection for $72 \mathrm{~h}$, the cells were harvested and stained in binding buffer with $5 \mu \mathrm{l}$ of Annexin V-FITC for $10 \mathrm{~min}$ at 
Table I. List of primers.

Primer

\begin{tabular}{ll}
\hline Name & \multicolumn{1}{c}{ Sequence (5'-3') ${ }^{\mathrm{a}}$} \\
\hline APC2 F & AAGGTGGAGGTGGTCTTCTGG \\
APC2 R & GGTGCCGTGGAGGATTTGC \\
U6 F & CTCGCTTCGGCAGCACA \\
U6 R & AACGCTTCACGAATTTGCGT \\
GAPDH F & AAGGTGAAGGTCGGAGTCA \\
GAPDH R & GGAAGATGGTGATGGGATT \\
\hline
\end{tabular}

Primers for 3'UTR cloning

\begin{tabular}{ll}
\hline Name & \multicolumn{1}{c}{ Sequence $\left(5^{\prime}-3^{\prime}\right)^{\mathrm{a}}$} \\
\hline APC2-UTR F & CGGAGCTCCGTGGTGGCAGCGA \\
& TGAT \\
APC2-UTR R & CGCGTCGACAGTGGCGGTCACT \\
& GTCCAT \\
APC2-MUT F & GCCTTCTCCATCCCCTGCCGTGG \\
& GCCGGTGAG \\
APC2-MUT R & GGCGGTGAGGTGTGGCTCACCG \\
& GCCCACGG
\end{tabular}

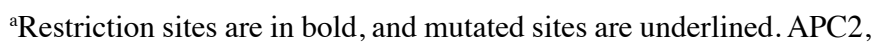
adenomatous polyposis coli 2 ; F, forward primer; $\mathrm{R}$, reverse primer; UTR, untranslated region; MUT, mutated.

room temperature. Following incubation with $5 \mu$ l of propidium iodide for $20 \mathrm{~min}$ at $4^{\circ} \mathrm{C}$, the cell apoptosis rate was analyzed via flow cytometry (FACScan; BD Biosciences). BD FACSDiva ${ }^{\mathrm{TM}}$ software (version 6.1.3) was used to analyze the flow cytometry data. The experiments were performed in triplicate.

Dual-luciferase reporter assay. APC2 was predicted to be the target candidate gene of miR-663b according to TargetScan databases (version 7.2) (17-21). The 3'UTR fragment of APC2 containing the putative wild-type (wt) sequence was amplified by PCR. The amplified product was inserted into the pmirGLO Dual-Luciferase miRNA Target Expression Vector (Promega Corporation). The QuikChange Lightning Site-Directed Mutagenesis Kit (Stratagene; Agilent Technologies, Inc.) was used to construct the miR-663b binding site mutants according to the manufacturer's protocol. These constructs were named pmirGLO-APC2-wt and pmirGLO-APC2-mutant (mut), respectively. SW480 cells were plated into $24-$ well plates at a density of $\sim 2 \times 10^{5}$ cells/well, cultured until they reached $\sim 70 \%$ confluence and co-transfected with either miR-663b mimic or $\mathrm{NC}$ and pmirGLO-APC2-wt or pmirGLO-APC2-mut using Lipofectamine 2000 (Invitrogen; Thermo Fisher Scientific, Inc.). Transfected cells were collected after $48 \mathrm{~h}$ of incubation, and the luciferase activity was measured by a Dual-Luciferase Reporter Assay System (Promega Corporation) in accordance with the manufacturer's protocol. The relative luciferase activity, normalized using Renilla luciferase, was measured $48 \mathrm{~h}$ after transfection. All experiments were performed in triplicate.

Statistical analysis. Experimental data are presented as mean \pm standard deviation. All data were analyzed using one-way ANOVA or Student's t-test. Multiple comparisons between the groups were performed using Tukey's post hoc test. SPSS software v.18.0 (SPSS, Inc.) was used for all data analyses. $\mathrm{P}<0.05$ was considered to indicate a statistically significant difference.

\section{Results}

miR-663b is highly expressed in CRC tissues and cell lines. To validate the expression of miR-663b in CRC tissues, the expression level of miR-663b was detected in 20 paired CRC tissue specimens and adjacent normal tissues. The results revealed that miR-663b expression was significantly increased in CRC tissues compared with that in adjacent normal tissues (Fig. 1A). To further investigate the expression pattern of miR-663b in CRC cells, RT-qPCR was performed to measure the expression of miR-663b in 4 CRC cell lines and the normal colonic cell line FHC. It was observed that miR-663b was markedly upregulated in all $4 \mathrm{CRC}$ cell lines compared with FHC cells (Fig. 1A). These data suggest that the abnormal expression of miR-663b may be involved in tumorigenesis of human CRC. As the expression level of miR-663B was the lowest in SW480 and highest in HCT-116 among 4 CRC cell lines, the SW480 and HCT-116 cells were selected for the subsequent gain/loss-of-function studies and investigation of the underlying mechanism.

miR-663b promotes $C R C$ cell proliferation. The overexpression miR-663b in CRC tissues and cells suggested that miR-663b may serve as an oncogene in CRC. To investigate the biological function of miR-663b, its effect on the proliferation of CRC cells was examined using a CCK-8 assay. miR-663b expression was measured using RT-qPCR to confirm the transfection efficiency of ectopic miR-663b mimic or inhibitor (Fig. 1B). It was demonstrated that ectopic miR-663b expression markedly increased the proliferation of SW480 cells (Fig. 2A), while miR-663b knockdown decreased the proliferation of HCT-116 cells at 3 and 4 days after transfection (Fig. 2B).

miR-663b decreases apoptosis of CRC cells. Following transfection of miR-663b mimic or inhibitor for $72 \mathrm{~h}, \mathrm{CRC}$ cell apoptosis was analyzed using flow cytometry. The apoptotic rate was significantly decreased in the miR-663b mimic-transfected group compared with the miR-NC group (Fig. 2C). Additionally, the apoptotic rate in the miR-663b inhibitor group was increased compared with that in the corresponding NC group (Fig. 2D). These results confirmed the anti-apoptotic effect of miR-663b on CRC cells.

miR-663b promotes the migration and invasion in CRC cells. To evaluate the role of miR-663b in cancer cell migration and invasion, wound healing and Transwell assays were performed. It was observed that the ectopic expression of miR-663b promoted SW480 cell migration (Fig. 3A), whereas miR-663b inhibitor decreased HCT-116 cell migration (Fig. 3B). In 

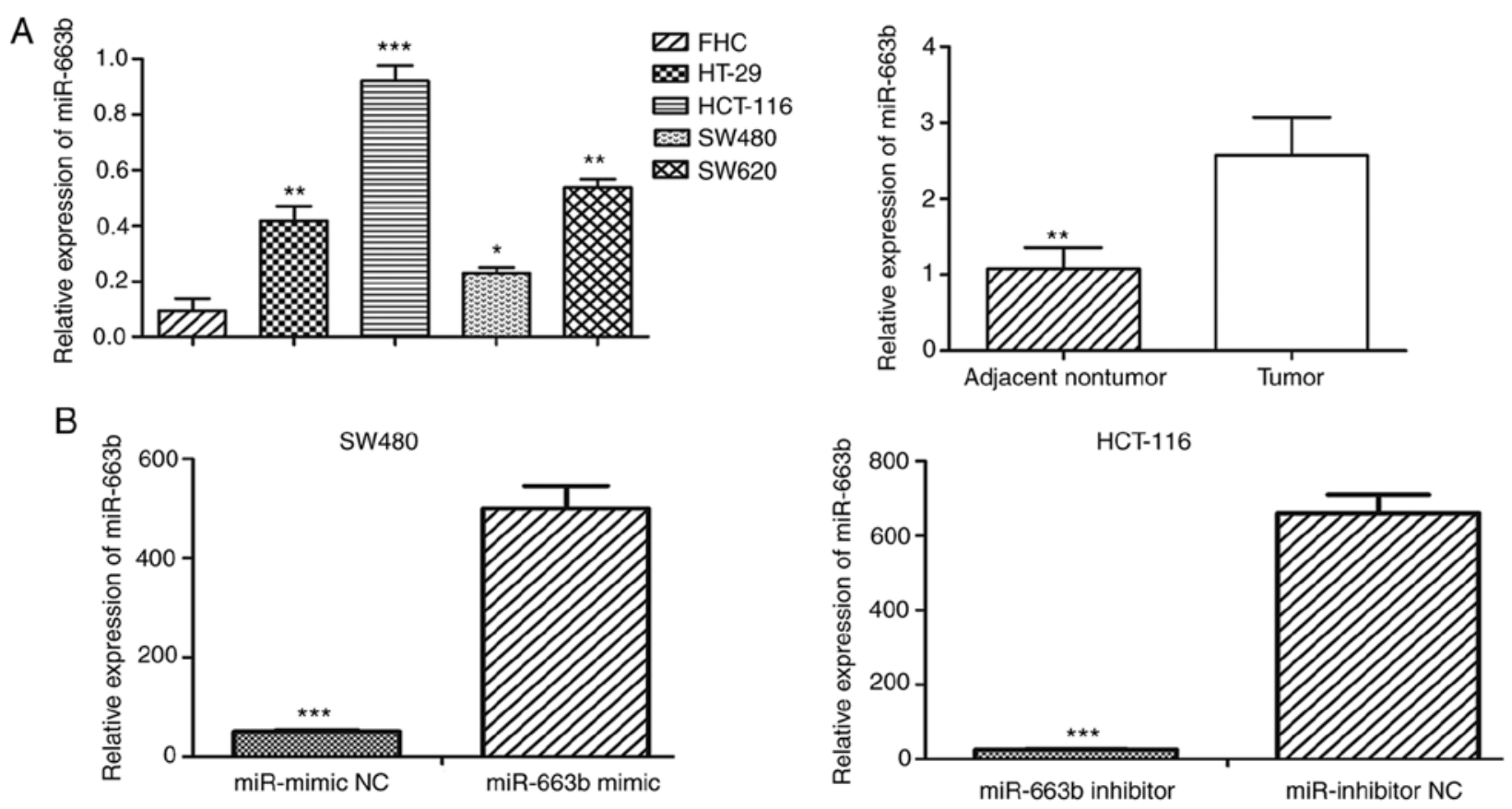

Figure 1. Expression levels of miR-663b in CRC tissues and cell lines. (A) miR-663b expression was markedly upregulated in the CRC tissues and cell lines compared with the corresponding NC group. (B) SW480 cells transfected with miR-663b mimic exhibited an increase in miR-663b expression, while HCT-116 cells transfected with miR-663b inhibitor demonstrated a significantly decreased miR-663b expression. The expression of miR-663b was normalized to small nuclear RNA U6. ${ }^{*} \mathrm{P}<0.05,{ }^{* * *} \mathrm{P}<0.01$ and ${ }^{* * *} \mathrm{P}<0.001$. vs. respective control. miR, microRNA; CRC, colorectal cancer; NC, negative control.

addition, the invasion assay suggested that ectopic miR-663b expression markedly promoted the invasion capacity of SW480 cells (Fig. 4A), while miR-663b knockdown inhibited invasion of HCT-116 cells (Fig. 4B). These results indicated that miR-663b may be involved in CRC progression by promoting cell migration and invasion.

APC2 is a direct functional target of $m i R-663 \mathrm{~b}$. To elucidate the molecular mechanism by which miR-663b promotes cancer cell proliferation and invasion, its target gene was further investigated. APC2, a negative invasion-associated regulator in the $\mathrm{Wnt} / \beta$-catenin signaling pathway, was selected as the candidate target. A seed sequence of miR-663b was bound to the putative 3'UTR of APC2 (Fig. 5A). First, a dual-luciferase reporter system was employed to confirm whether APC2 is a target of miR-663b. PmirGLO-APC2-wt or pmirGLO-APC2-mut was co-transfected with either miR-NC or miR-663b mimic in SW480 cells. It was observed that ectopic miR-663b significantly inhibited the firefly luciferase activity of PmirGLO-APC2-wt but not pmirGLO-APC2-mut (Fig. 5B), suggesting that APC2 is a direct target of miR-663b.

In addition, to further validate that APC2 is the target of miR-663b, western blot analysis and RT-qPCR analysis were performed to evaluate the effect of miR-663b on endogenous APC2 expression at the protein and mRNA level. The results demonstrated that the miR-663b inhibited the expression of the APC2 protein in SW480 cells and that the miR-663b inhibitor upregulated the APC2 level in HCT-116 cells (Fig. 5C). However, miR-663b overexpression did not decrease the APC2 mRNA level ( $\mathrm{P}>0.05$; Fig. 5D), indicating that miR-663b downregulates APC2 expression at the post-transcriptional level. Taken together, these data suggest that miR-663b may downregulate the expression of APC2 by directly targeting its 3'UTR.
miR-663b is involved in cancer cell invasion through activating the Wnt/ $\beta$-catenin pathway. Further experiments were conducted to explore the molecular mechanisms by which miR-663b promotes cell invasion by regulating APC2. The effect of APC2 knockdown on invasion was investigated. The expression of the APC2 protein was identified to be markedly downregulated in siAPC2-transfected SW480 cells (Fig. 3D). The data suggested that the knockdown of APC2 promoted CRC cell migration and invasion (Figs. 3C and 4C), eliciting the same effect as miR-663b overexpression.

Previous evidence has demonstrated that the $\mathrm{Wnt} / \beta$-catenin signaling pathway is associated with tumor growth and invasion (22). Therefore, the effect of miR-663b on the key molecules of the $\mathrm{Wnt} / \beta$-catenin pathway was investigated. It was observed that ectopic miR-663b expression promoted the expression of MYC proto-oncogene protein (c-Myc) and cyclin D1 protein in SW480 cells (Fig. 6A). In addition, the ectopic expression of miR-663b lowered the protein level of phosphorylated $\beta$-catenin. However, there was little effect on the endogenous expression of axin 1 or total $\beta$-catenin protein observed (Fig. 6A).

Collectively, these results suggest that miR-663b may promote cell migration and invasion in CRC through activating the $\mathrm{Wnt} / \beta$-catenin pathway (Fig. $6 \mathrm{~B}$ ).

\section{Discussion}

Accumulating evidence indicates that the dysregulation of miRNAs is involved in various types of diseases $(23,24)$. The abnormal expression of miR-663b has been observed in a variety of malignancies: Shu et al (25) demonstrated that the knockdown of miR-663b inhibited cell proliferation and promoted apoptosis in osteosarcoma by regulating tumor 

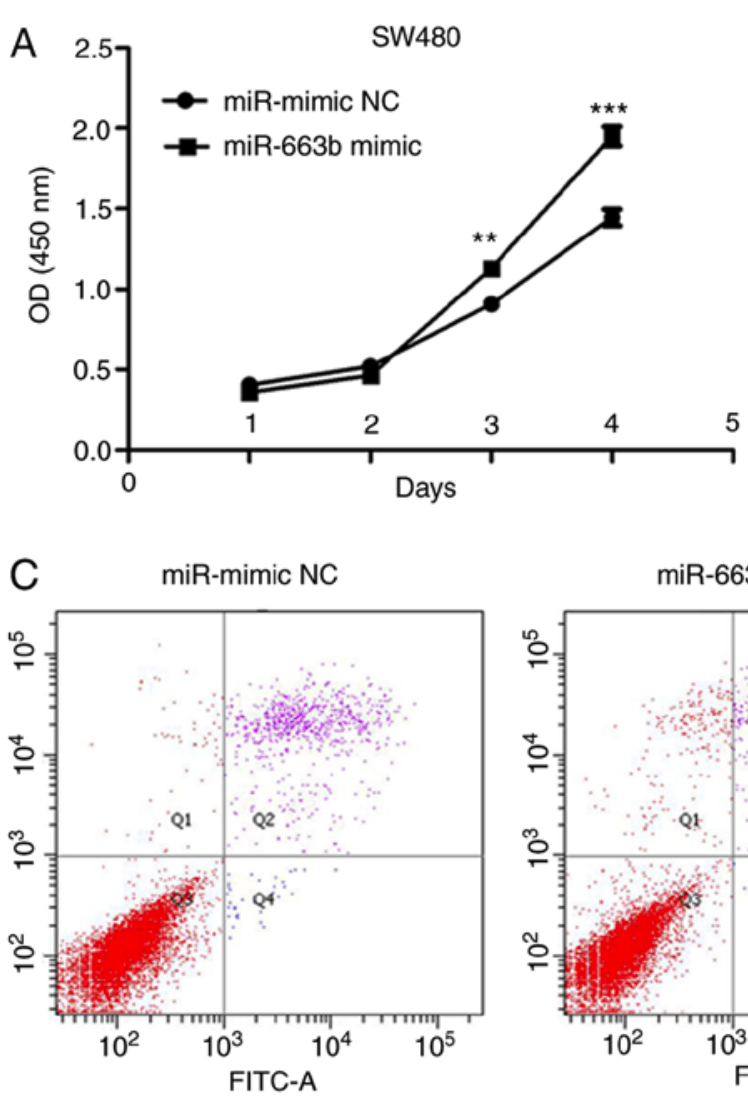

D

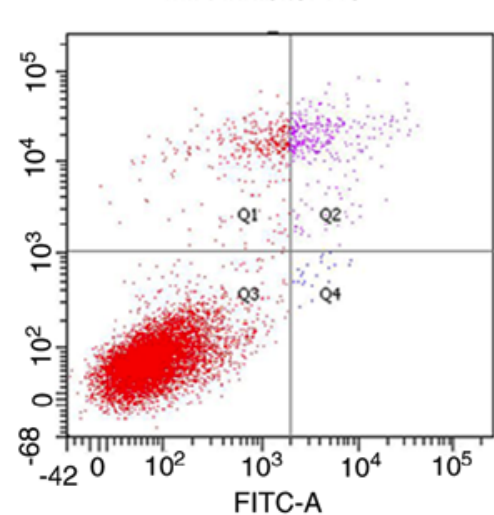

B

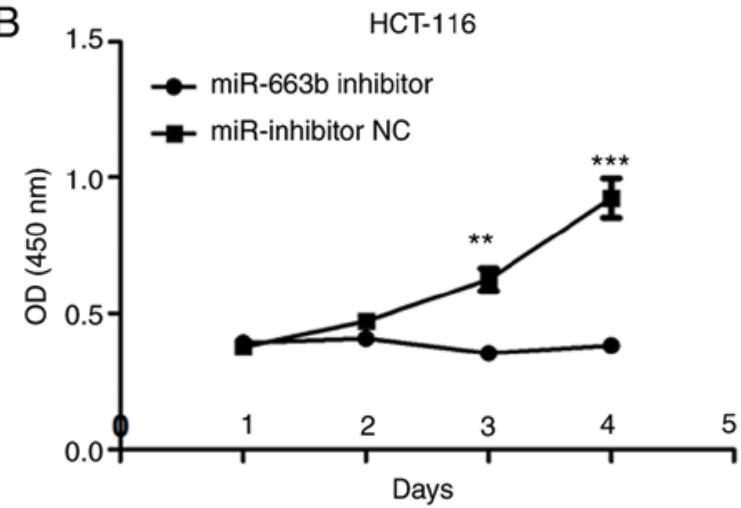

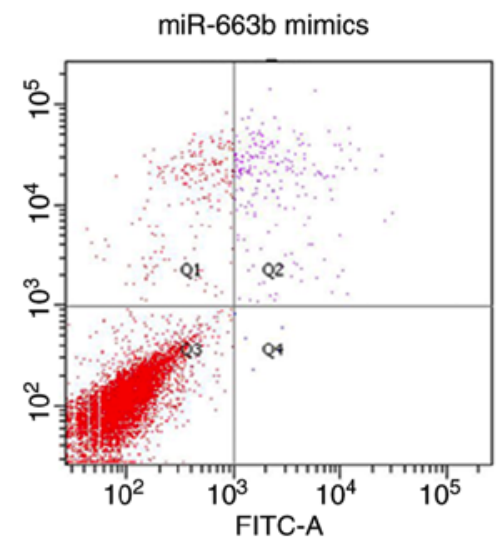

miR-663b inhibitor

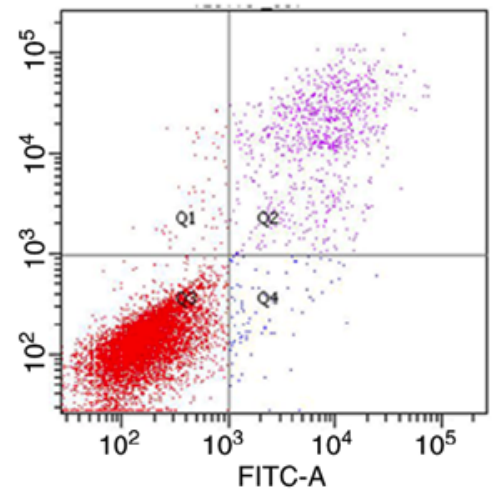

SW480

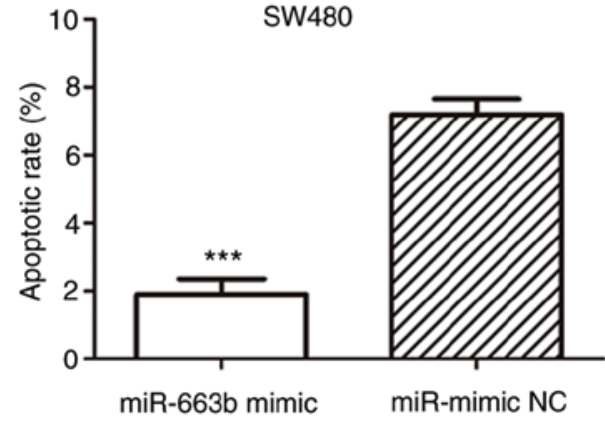

HCT-116

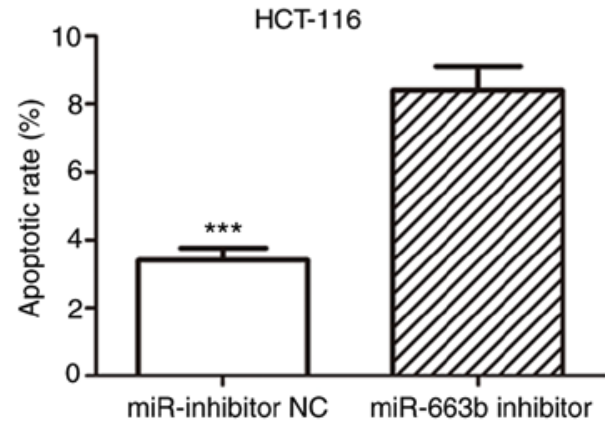

Figure 2. Effect of miR-663b on cell proliferation and apoptosis. The effects of miR-663b on the proliferation of colorectal cancer (A) SW480 and (B) HCT-116 cells were measured via a Cell Counting Kit-8 assay. Apoptosis rates in (C) SW480 and (D) HCT-116 cells were analyzed via flow cytometry. Data are presented as the mean of 3 measurements and the bars represent the standard deviation. ${ }^{* * *} \mathrm{P}<0.01$ and ${ }^{* * * *} \mathrm{P}<0.001$ vs. NC. miR, microRNA; NC, negative control; FITC, fluorescein isothiocyanate.

protein p73 expression; Du et al (26) identified that miR-497 and miR-663b levels in the plasma may be novel biomarkers for bladder cancer; Cai et al (27) suggested that the epigenetic inhibition of miR-663b by HOTAIR promotes cell proliferation in pancreatic cancer by upregulating insulin-like growth factor 2; Wang et al (28) reported that miR-663b promotes cell proliferation and epithelial-to-mesenchymal transition by directly targeting SMAD7 in nasopharyngeal carcinoma; Wang et al (29) demonstrated that pterostilbene dose-dependently inhibited cell proliferation in human endometrial cancer by downregulating miR-663b, and BCL2L14 was verified as a direct target of miR-663b; Liang et al (30) revealed that miR-663b promotes migration and invasion of nasopharyngeal carcinoma cells through downregulating TUSC2; and, using a miRNA microarray analysis, Pellatt et al (15) recently demonstrated that miR-663b is upregulated in CRC tissues compared with normal mucosa. However, the mechanism of action of miR-663b in CRC remains elusive.

In the present study, the expression pattern of miR-663b in CRC cell lines was first investigated, and it was identified that miR-663b expression was upregulated in 4 CRC cell lines compared with FHC cells. This abnormal expression suggests that miR-663b is likely involved in certain biological properties of CRC. The function and relative regulatory mechanisms of miR-663b in CRC tumorigenesis were additionally investigated, and the results demonstrated that ectopic miR-663b 
A

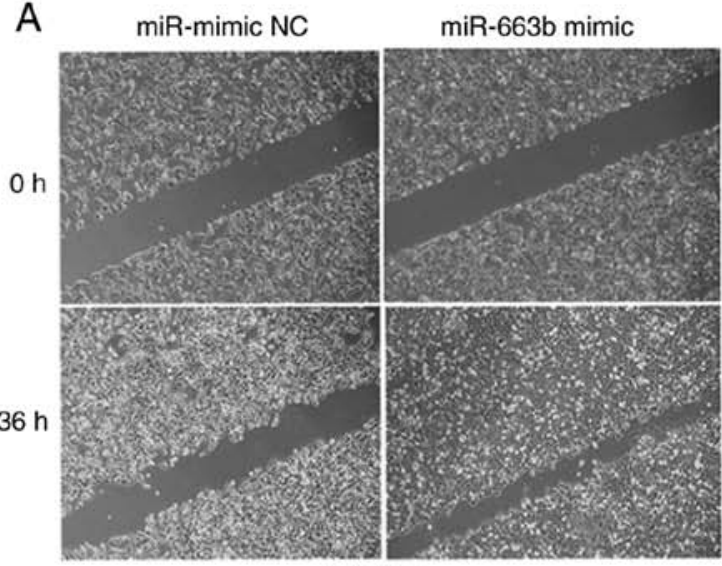

SW480

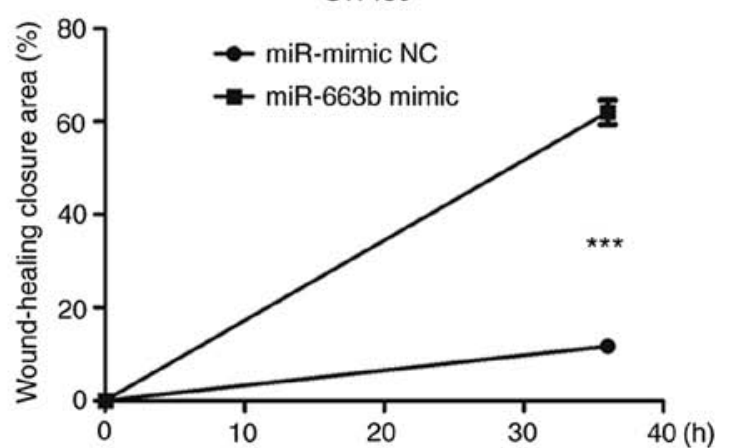

C

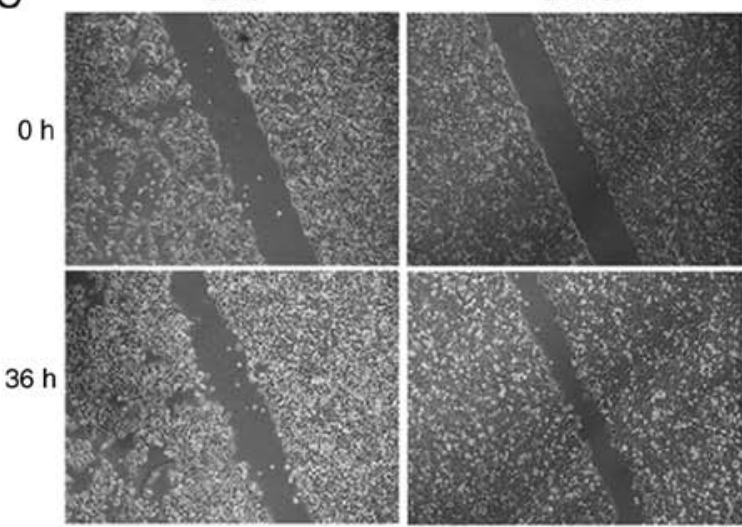

SW480

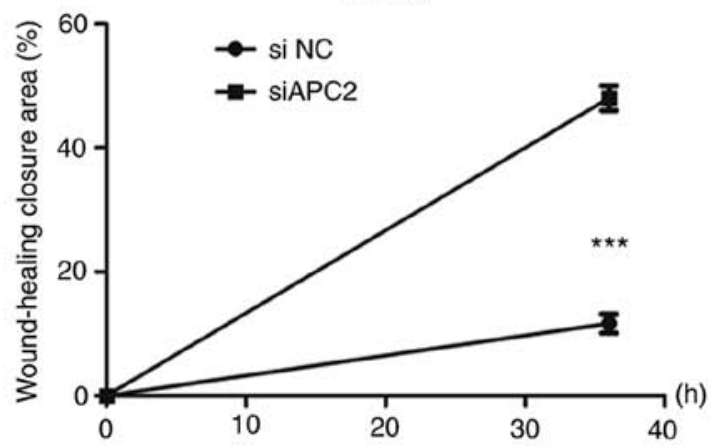

B

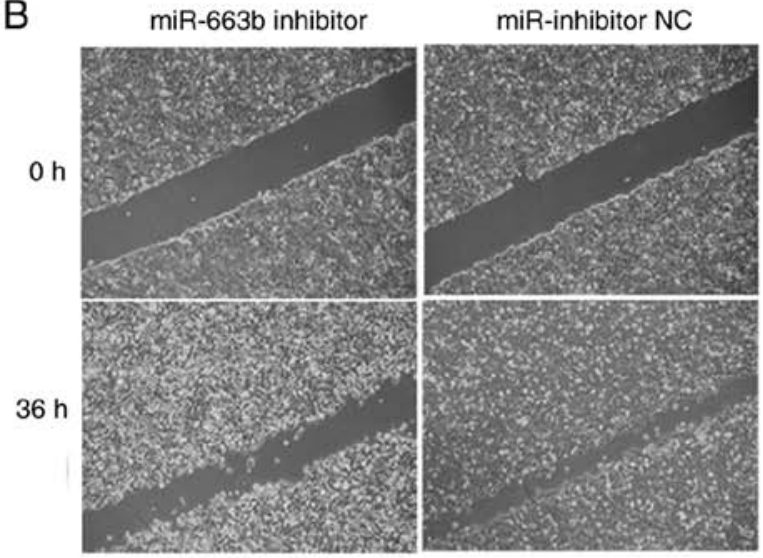

HCT-116
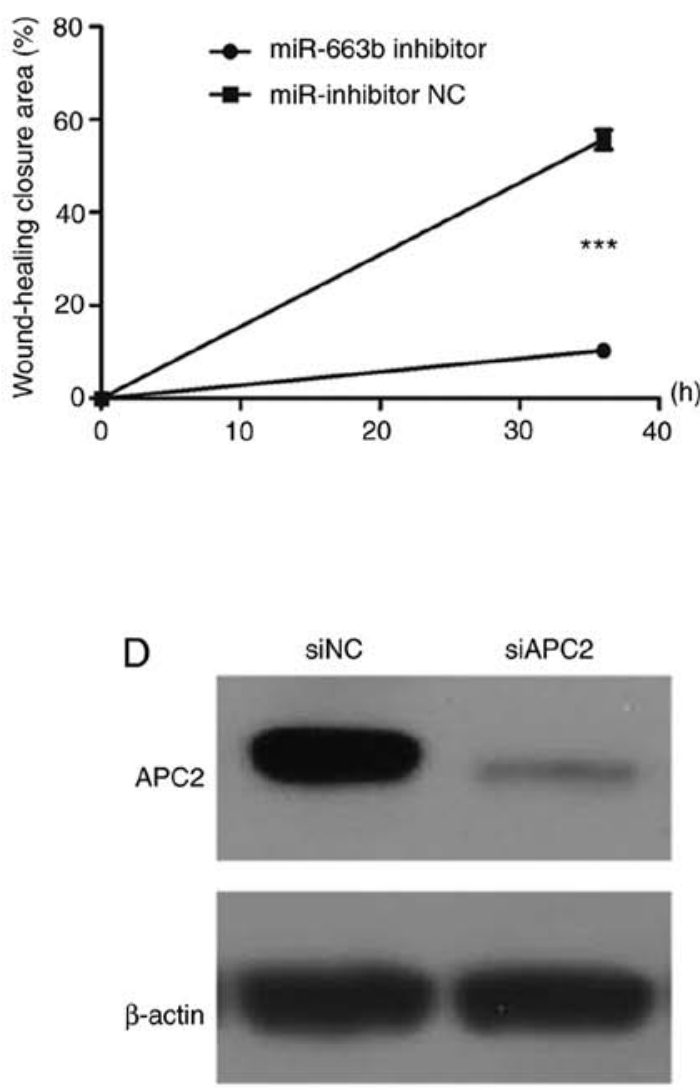

SW480

Figure 3. Effects of miR-663b and siAPC2 on migration of colorectal cancer cells were evaluated via a wound healing assay. (A) The ectopic expression of miR-663b promoted SW480 cell migration. (B) miR-663b knockdown inhibited HCT-116 cell migration. (C) APC2 knockdown elicited the same effect as ectopic miR-663b on migration. (D) siRNA targeting APC2 significantly downregulated the APC2 protein level. ${ }^{* * *}$ P $<0.001$ vs. NC. miR, microRNA; si, small interfering; APC2, adenomatous polyposis coli 2; NC, negative control. Magnification, x40.

expression promoted cell proliferation, migration and invasion, and decreased apoptosis in vitro. It was demonstrated that dysregulation of APC serves important role in breast cancer cell invasion through WNT signaling pathway (31). The present study revealed that the overexpression of microRNA-663b promotes CRC cell invasion. However, the 
A

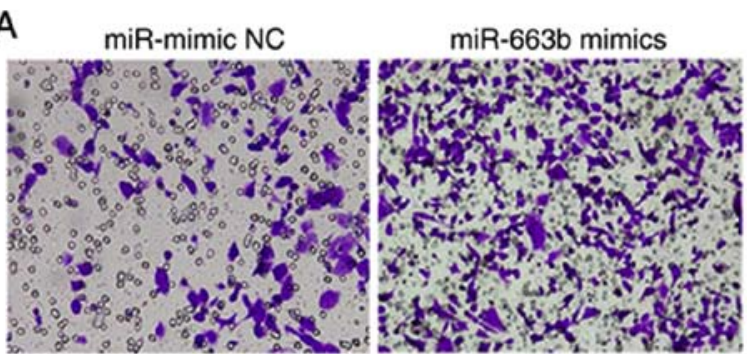

B

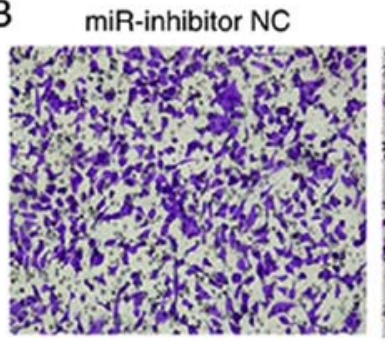

miR-663b inhibitor

C

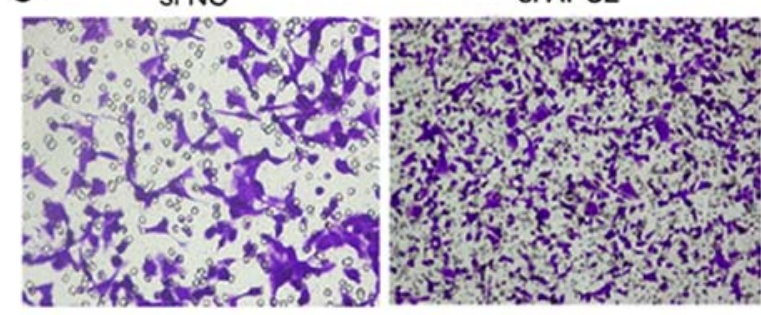

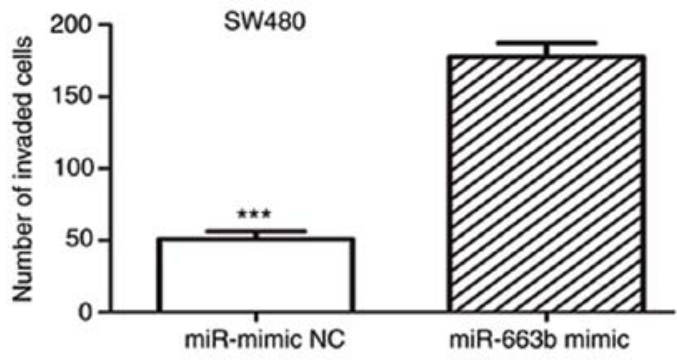

HCT-116

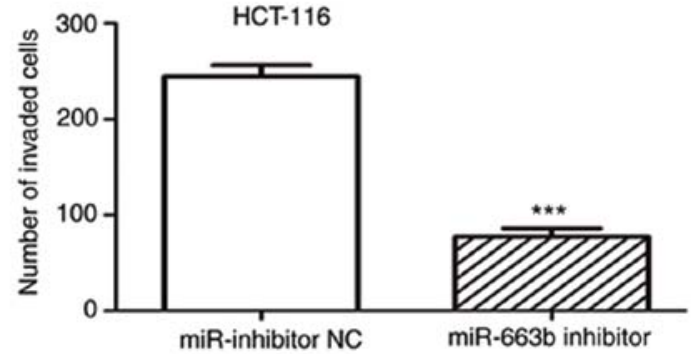

SW480

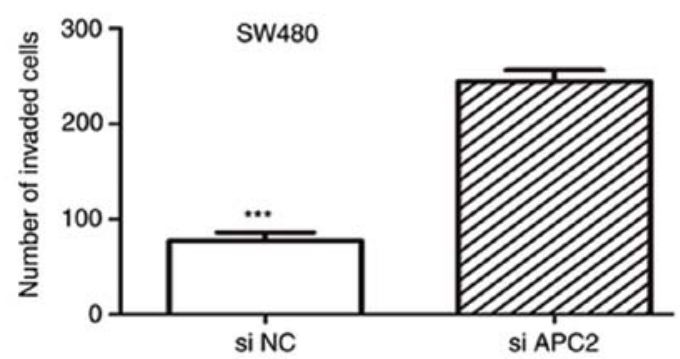

Figure 4. Effects of miR-663b and siAPC2 on invasion of colorectal cancer cells were evaluated via a Transwell invasion assay. (A) miR-663b overexpression significantly enhanced the invasive capacity of SW480 cells. (B) miR-663b knockdown inhibited invasion of HCT-116 cells. (C) APC2 knockdown elicited the same effect as ectopic miR-663b on invasion. Data are presented as the mean of 3 measurements and the bars represent the standard deviation. ${ }^{* * *} \mathrm{P}<0.001$ vs. NC. miR, microRNA; si, small interfering; APC2, adenomatous polyposis coli 2; NC, negative control. Magnification, x100.

A

$$
\begin{aligned}
& \text { 5' ... TCCCCTGCCGTGGGGGCCACAG...3' APC2 3' UTR Wt } \\
& \text { 3' ...GGAGUCCGUGCCGGCCCGGUGG...5' miR-663b } \\
& \text { 5' ... TCCCCTGCCGTGGG_CGGTGAG...3' APC2 3' UTR Mut }
\end{aligned}
$$

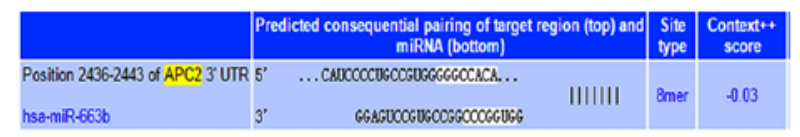

C

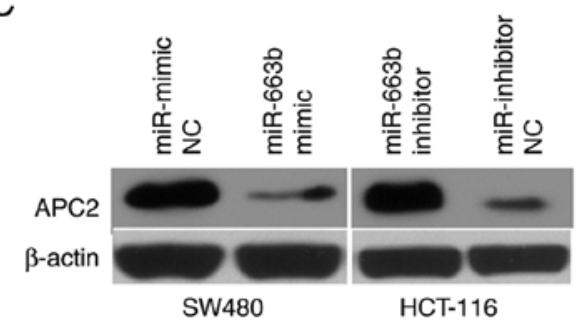

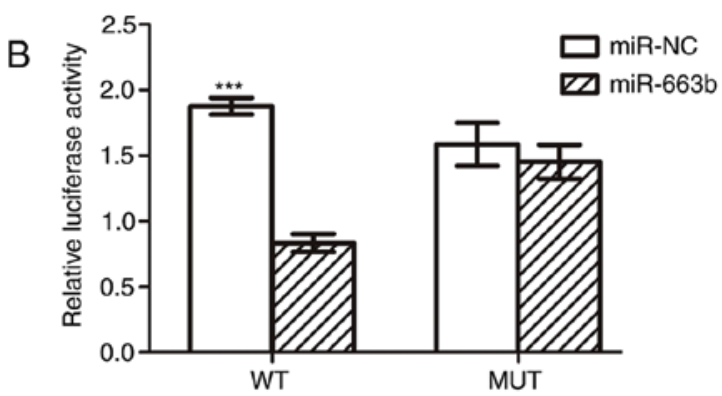

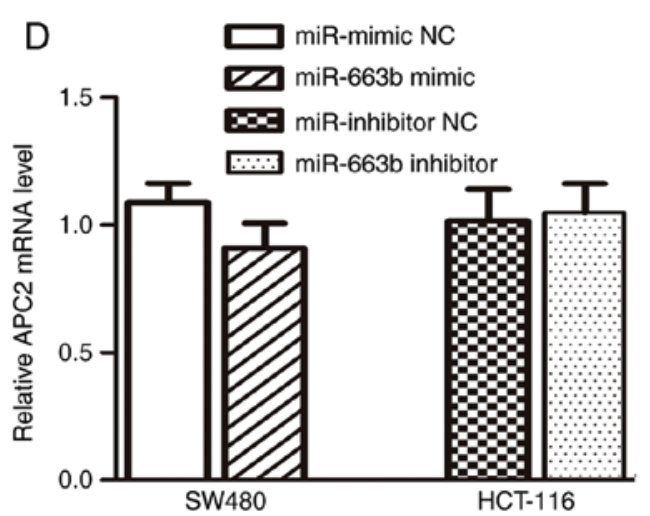

Figure 5. APC2 is a direct target of miR-663b in colorectal cancer. (A) The putative miR-663b binding sequence in the 3'UTR of APC2 mRNA. Mutation was generated on the APC2 3'UTR sequence in the complementary site for the seed region of miR-663b. (B) Analysis of luciferase activity. SW480 cells were co-transfected with either $100 \mathrm{nM}$ of miR-663b or NC and $200 \mathrm{ng}$ of pmirGLO-APC2-wt or pmirGLO-APC2-mut (indicated as WT or MUT on the X axis). The relative firefly luciferase activity normalized with Renilla luciferase was measured $48 \mathrm{~h}$ post-transfection. The effect of miR-663b on the expression of endogenous APC2 at the (C) protein and (D) mRNA levels. ${ }^{* * *} \mathrm{P}<0.001$ vs. NC. APC2, adenomatous polyposis coli 2 ; miR, microRNA; UTR, untranslated region; WT, wild-type; MUT, mutant; NC, negative control; hsa, Homo sapiens. 


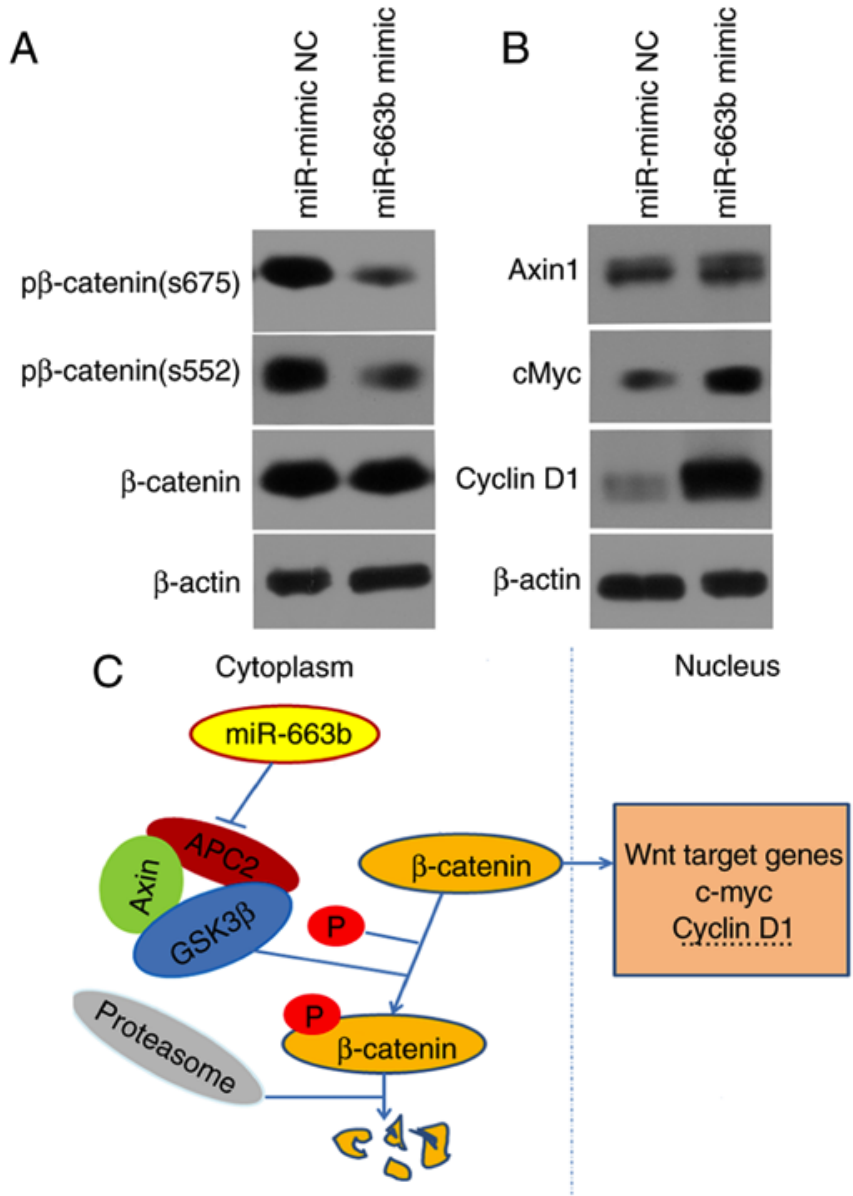

Figure 6. miR-663b was involved in cell invasion by activating the Wnt $/ \beta$-catenin signaling pathway. (A) Phosphorylation of the $\beta$-catenin protein on Ser552 and Ser675 is inhibited by miR-663b. (B) The effect of miR-663b on the expression of endogenous genes. miR-663b significantly promoted the expression levels of the downstream genes of the Wnt/ $\beta$-catenin signaling pathway. $\beta$-actin was used as the internal control. (C) Signaling pathways that regulate the cell invasion in colorectal cancer involving miR-663b. miR, microRNA; NC, negative control; APC2, adenomatous polyposis coli 2 ; GSK3 $\beta$, glycogen synthase kinase-3 $\beta$; p $\beta$-catenin, phosphorylated $\beta$-catenin.

molecular mechanism in miR-663b-regulated invasion in CRC remains unclear. Using bioinformatics analysis, APC2 was predicted to be a functional target of miR-663b in the present study. To elucidate the molecular mechanisms by which miR-663b regulates cell invasion, APC2 was selected as a target candidate for further investigation.

The APC gene is a well-known tumor suppressor that has been investigated in association with a number of malignancies (32-34). APC2, an APC homologue located on chromosome 19p13.3 (35), serves a key role in several human malignant diseases, such as retinoblastoma, lymphocytic leukemia and ovarian cancer (36-38). Previous studies have demonstrated that APC2 interacts with cytoplasmic $\beta$-catenin and negatively regulates the Wnt signaling pathway (39). Accumulating evidence suggests that APC2 is involved in the development and progression of several types of cancer (40).

The Wnt/ $\beta$-catenin signaling pathway is an important pathway that is associated with tumor growth and invasion (22). During Wnt signaling, $\beta$-catenin is a key molecule that serves as a co-regulator, cooperating with transcription factors to regulate gene expression. In the absence of Wnt signaling, the $\beta$-catenin protein is tightly controlled by a destruction complex that is composed of APC, axin and glycogen synthetase kinase- $3 \beta$. This complex then promotes $\beta$-catenin protein phosphorylation, ultimately leading to degradation of $\beta$-catenin by the proteasome system (41). The results from the present study indicated that the overexpression of microRNA-663b inhibited the degradation of $\beta$-catenin and activated the expression of downstream genes of $\beta$-catenin. To better demonstrate the conclusions from the present study, phosphorylation level of $\beta$-catenin should be detected at more phosphorylation sites such as S33, S37 and S45, which are involved in the degradation of $\beta$-catenin. Studies regarding this issue are being conducted by the present study group. The data from the present study suggested the involvement of $\beta$-catenin phosphorylation regulation, but the specific mechanism how microRNA-663b regulates $\beta$-catenin phosphorylation requires further investigation. Wnt signaling, however, inhibits the degradation of the $\beta$-catenin protein, allowing $\beta$-catenin to accumulate in the cytoplasm and enter the nuclei. $\beta$-catenin then binds with the T-cell factor/lymphoid-enhancing factor family molecules to activate Wnt responsive genes, such as c-myc and cyclin D1 (42). The present study revealed that the expression of APC2 was downregulated by miR- $663 \mathrm{~b}$. Therefore, the phosphorylation of $\beta$-catenin by glycogen synthase kinase-3 $\beta$ (GSK3 $\beta$ ) was decreased. However, unphosphorylated $\beta$-catenin protein was probably upregulated through a separate signaling pathway, which may explain why the total protein level of $\beta$-catenin appeared to be unchanged between the control and miR-663b groups. The other pathways through which $\beta$-catenin protein was regulated require further investigation. The results from the present study revealed that miR-663b inhibited the phosphorylation of $\beta$-catenin at residues S552 and S675, which may suppress downstream target gene expression. It has been suggested that the phosphorylation of $\beta$-catenin at residues S33, S37 and S45 by GSK3 $\beta$ and casein kinase I isoform $\alpha$ may inhibit $\beta$-catenin activity by degradation of $\beta$-catenin (43). As the expression of APC2 protein was downregulated by miR-663b, which inhibited phosphorylation of $\beta$-catenin by GSK3 $\beta$, the degradation of $\beta$-catenin was decreased. Therefore, $\beta$-catenin accumulates in cytoplasm and translocates to the nuclei, where it associates with members of the T-cell factor/lymphoid-enhancing factor family of transcription factor to turn on Wnt target genes such as c-myc and cyclin D1. Consequently, c-Myc and cyclin D1 were upregulated in miR-663b-overexpressed cells.

The present study demonstrated that APC2 is a functional target of miR-663b, suggested that the Wnt $/ \beta$-catenin signaling pathways are involved in miR-663b-regulated cancer cell invasion, and that downregulation of APC 2 by miR-663b induction may serve a crucial role in the development and progression of CRC. The results of the present study also indicated that miR-663b promoted CRC cell invasion. To further explore whether APC2 was the direct functional target of miR-663b, invasion assays were performed following APC2 silencing. The results revealed that miR-663b promoted CRC cell invasion through directly targeting APC2. A number of other genes may be involved in miR-663b-regulated cell invasion, which requires further investigation. Furthermore, the clinical 
significance of the dysregulation of miR-663b requires further investigation.

In summary, the results of the present study revealed that miR-663b acts as an oncogene by promoting cell proliferation, migration and invasion by directly targeting the tumor suppressor gene APC2. It was inferred that miR-663b may serve a key role in the development and progression of CRC and may represent a novel therapeutic target for CRC.

\section{Acknowledgements}

Not applicable.

\section{Funding}

No funding was received.

\section{Availability of data and materials}

All data generated or analyzed during this study are included in this published article.

\section{Authors' contributions}

FX and GZ conceived and designed the present study. FX drafted the initial manuscript. FX and CY performed all the experiments. WC participated in data analysis and interpretation. All authors read and approved the final manuscript.

\section{Ethics approval and consent to participate}

The present study was approved by the Ethics Committee of the Union Hospital, Tongji Medical College, Huazhong University of Science and Technology.

\section{Patient consent for publication}

Not applicable.

\section{Competing interests}

The authors declare that they have no competing interests.

\section{References}

1. Jemal A, Siegel R, Ward E, Hao Y, Xu J, Murray T and Thun MJ: Cancer statistics, 2008. CA Cancer J Clin 58: 71-96, 2008.

2. Obuch JC and Ahnen DJ: Colorectal cancer: Genetics is changing everything. Gastroenterol Clin North Am 45: 459-476, 2016.

3. DeSantis CE, Lin CC, Mariotto AB, Siegel RL, Stein KD, Kramer JL, Alteri R, Robbins AS and Jemal A: Cancer treatment and survivorship statistics, 2014. CA Cancer J Clin 64: 252-271, 2014.

4. Bartel DP: MicroRNAs: Genomics, biogenesis, mechanism, and function. Cell 116: 281-297, 2004.

5. Ambros V: The functions of animal microRNAs. Nature 431: 350-355, 2004

6. Moriyama T, Ohuchida K, Mizumoto K, Yu J, Sato N, Nabae T, Takahata S, Toma H, Nagai E and Tanaka M: MicroRNA-21 modulates biological functions of pancreatic cancer cells including their proliferation, invasion, and chemoresistance. Mol Cancer Ther 8: 1067-1074, 2009.

7. Bhaumik D, Scott GK, Schokrpur S, Patil CK, Campisi J and Benz CC: Expression of microRNA-146 suppresses NF-kappaB activity with reduction of metastatic potential in breast cancer cells. Oncogene 27: 5643-5647, 2008.
8. Hu G, Chen D, Li X, Yang K, Wang H and Wu W: miR-133b regulates the MET proto-oncogene and inhibits the growth of colorectal cancer cells in vitro and in vivo. Cancer Biol Ther 10: 190-197, 2010.

9. Esquela-Kerscher A and Slack FJ: Oncomirs-microRNAs with a role in cancer. Nat Rev Cancer 6: 259-269, 2006.

10. Wang Z, Zhang X, Yang Z, Du H, Wu Z, Gong J, Yan J and Zheng Q: MiR-145 regulates PAK4 via the MAPK pathway and exhibits an antitumor effect in human colon cells. Biochem Biophys Res Commun 427: 444-449, 2012.

11. Wu L, Cai C, Wang X, Liu M, Li X and Tang H: MicroRNA-142-3p, a new regulator of RAC1, suppresses the migration and invasion of hepatocellular carcinoma cells. FEBS Lett 585: 1322-1330, 2011.

12. Liu C, Yu J, Yu S, Lavker RM, Cai L, Liu W, Yang K, He X and Chen S: MicroRNA-21 acts as an oncomir through multiple targets in human hepatocellular carcinoma. J Hepatol 53: 98-107, 2010.

13. Shen K, Liang Q, Xu K, Cui D, Jiang L, Yin P, Lu Y, Li Q and Liu J: MiR-139 inhibits invasion and metastasis of colorectal cancer by targeting the type I insulin-like growth factor receptor. Biochem Pharmacol 84: 320-330, 2012.

14. Xu K, Chen G, Qiu Y, Yuan Z, Li H, Yuan X, Sun J, Xu J, Liang X and Yin P: miR-503-5p confers drug resistance by targeting PUMA in colorectal carcinoma. Oncotarget 8: 21719-21732, 2017.

15. Pellatt DF, Stevens JR, Wolff RK, Mullany LE, Herrick JS, Samowitz W and Slattery ML: Expression profiles of miRNA subsets distinguish human colorectal carcinoma and normal colonic mucosa. Clin Transl Gastroenterol 7: e152, 2016.

16. Livak KJ and Schmittgen TD: Analysis of relative gene expression data using real-time quantitative PCR and the 2(-Delta Delta $\mathrm{C}(\mathrm{T}))$ method. Methods 25: 402-408, 2001.

17. Agarwal V, Bell GW, Nam JW and Bartel DP: Predicting effective microRNA target sites in mammalian mRNAs. Elife 4, 2015.

18. Friedman RC, Farh KK, Burge CB and Bartel DP: Most mammalian mRNAs are conserved targets of microRNAs. Genome Res 19: 92-105, 2009.

19. Garcia DM, Baek D, Shin C, Bell GW, Grimson A and Bartel DP: Weak seed-pairing stability and high target-site abundance decrease the proficiency of 1sy- 6 and other microRNAs. Nat Struct Mol Biol 18: 1139-1146, 2011.

20. Grimson A, Farh KK, Johnston WK, Garrett-Engele P, Lim LP and Bartel DP: MicroRNA targeting specificity in mammals: Determinants beyond seed pairing. Mol Cell 27: 91-105, 2007.

21. Lewis BP, Burge CB and Bartel DP: Conserved seed pairing, often flanked by adenosines, indicates that thousands of human genes are microRNA targets. Cell 120: 15-20, 2005.

22. Jeanes A, Gottardi CJ and Yap AS: Cadherins and cancer: How does cadherin dysfunction promote tumor progression? Oncogene 27: 6920-6929, 2008.

23. Sarver AL, French AJ, Borralho PM, Thayanithy V, Oberg AL, Silverstein KA, Morlan BW, Riska SM, Boardman LA, Cunningham JM, et al: Human colon cancer profiles show differential microRNA expression depending on mismatch repair status and are characteristic of undifferentiated proliferative states. BMC Cancer 9: 401, 2009.

24. Schetter AJ, Leung SY, Sohn JJ, Zanetti KA, Bowman ED, Yanaihara N, Yuen ST, Chan TL, Kwong DL, Au GK, et al: MicroRNA expression profiles associated with prognosis and therapeutic outcome in colon adenocarcinoma. JAMA 299: 425-436, 2008.

25. Shu Y, Ye W, Gu YL and Sun P: Blockade of miR-663b inhibits cell proliferation and induces apoptosis in osteosarcoma via regulating TP73 expression. Bratisl Lek Listy 119: 41-46, 2018.

26. Du M, Shi D, Yuan L, Li P, Chu H, Qin C, Yin C, Zhang Z and Wang M: Circulating miR-497 and miR-663b in plasma are potential novel biomarkers for bladder cancer. Sci Rep 5: 10437, 2015.

27. Cai H, An Y, Chen X, Sun D, Chen T, Peng Y, Zhu F, Jiang Y and $\mathrm{He} \mathrm{X}$ : Epigenetic inhibition of miR-663b by long non-coding RNA HOTAIR promotes pancreatic cancer cell proliferation via up-regulation of insulin-like growth factor 2. Oncotarget 7: 86857-86870, 2016.

28. Wang M, Jia M and Yuan K: MicroRNA-663b promotes cell proliferation and epithelial mesenchymal transition by directly targeting SMAD7 in nasopharyngeal carcinoma. Exp Ther Med 16: 3129-3134, 2018.

29. Wang YL, Shen Y, Xu JP, Han K, Zhou Y, Yang S, Yin JY, Min DL and Hu HY: Pterostilbene suppresses human endometrial cancer cells in vitro by down-regulating miR-663b. Acta Pharmacol Sin 38: 1394-1400, 2017. 
30. Liang S, Zhang N, Deng Y, Chen L, Zhang Y, Zheng Z, Luo W, Lv Z, Li S and Xu T: miR-663b promotes tumor cell proliferation, migration and invasion in nasopharyngeal carcinoma through targeting TUSC2. Exp Ther Med 14: 1095-1103, 2017.

31. Cho SG: APC downregulated 1 inhibits breast cancer cell invasion by inhibiting the canonical WNT signaling pathway. Oncol Lett 14: 4845-4852, 2017.

32. Esteller M, Sparks A, Toyota M, Sanchez-Cespedes M, Capella G, Peinado MA, Gonzalez S, Tarafa G, Sidransky D, Meltzer SJ, et al: Analysis of adenomatous polyposis coli promoter hypermethylation in human cancer. Cancer Res 60: 4366-4371, 2000.

33. Liu M, Cui LH, Li CC and Zhang L: Association of APC, GSTP1 and SOCS1 promoter methylation with the risk of hepatocellular carcinoma: A meta-analysis. Eur J Cancer Prev 24: 470-483, 2015

34. Chen Y, Li J, Yu X, Li S, Zhang X, Mo Z and Hu Y: APC gene hypermethylation and prostate cancer: A systematic review and meta-analysis. Eur J Hum Genet 21: 929-935, 2013.

35. Kinzler KW, Nilbert MC, Su LK, Vogelstein B, Bryan TM, Levy DB, Smith KJ, Preisinger AC, Hedge P, McKechnie D, et al: Identification of FAP locus genes from chromosome $5 \mathrm{q} 21$. Science 253: 661-665, 1991.

36. Beta M, Chitipothu S, Khetan V, Biswas J and Krishnakumar S: Hypermethylation of adenomatosis polyposis coli-2 and its tumor suppressor role in retinoblastoma. Curr Eye Res 40: 719-728, 2015.

37. Rahmatpanah FB, Carstens S, Hooshmand SI, Welsh EC, Sjahputera O, Taylor KH, Bennett LB, Shi H, Davis JW, Arthur GL, et al: Large-scale analysis of DNA methylation in chronic lymphocytic leukemia. Epigenomics 1: 39-61, 2009.
38. Ying X, Li-ya Q, Feng Z, Yin W and Ji-hong L: MiR-939 promotes the proliferation of human ovarian cancer cells by repressing APC2 expression. Biomed Pharmacother 71: 64-69, 2015.

39. Nakagawa H, Murata Y, Koyama K, Fujiyama A, Miyoshi Y, Monden M, Akiyama T and Nakamura Y: Identification of a brain-specific APC homologue, APCL, and its interaction with beta-catenin. Cancer Res 58: 5176-5181, 1998.

40. Jarrett CR, Blancato J, Cao T, Bressette DS, Cepeda M, Young PE, King CR and Byers SW: Human APC2 localization and allelic imbalance. Cancer Res 61: 7978-7984, 2001.

41. Rubinfeld B, Souza B, Albert I, Müller O, Chamberlain SH, Masiarz FR, Munemitsu S and Polakis P: Association of the APC gene product with beta-catenin. Science 262: 1731-1734, 1993.

42. Behrens J, von Kries JP, Kühl M, Bruhn L, Wedlich D, Grosschedl R and Birchmeier W: Functional interaction of beta-catenin with the transcription factor LEF-1. Nature 382: 638-642, 1996.

43. Bustos VH, Ferrarese A, Venerando A, Marin O, Allende JE and Pinna LA: The first armadillo repeat is involved in the recognition and regulation of beta-catenin phosphorylation by protein kinase CK1. Proc Natl Acad Sci USA 103: 19725-19730, 2006.

(i) (9) This work is licensed under a Creative Commons Attribution-NonCommercial-NoDerivatives 4.0 International (CC BY-NC-ND 4.0) License. 